\title{
Hydrodynamic behaviour and comparison of technologies for the removal of excess biomass in gas-phase biofilters
}

\author{
J.A. Mendoza, Ó.J. Prado, M.C. Veiga, C. Kennes \\ Water Research, Volume 38, Issue 2, January 2004, Pages 404-413 \\ DOI: $10.1016 /$ j.watres.2003.09.014
}

\begin{abstract}
The hydrodynamic behaviour of a biofilter fed toluene and packed with an inert carrier was evaluated on start-up and after long-term operation, using both methane and styrene as tracers in Residence Time Distribution experiments. Results indicated some deviation from ideal plug flow behaviour after 2-year operation. It was also observed that the retention time of VOCs gradually increased with time and was significantly longer than the average residence time of the bulk gas phase. Non-ideal hydrodynamic behaviour in packed beds may be due to excess biomass accumulation and affects both reactor modeling and performance. Therefore, several methods were studied for the removal of biomass after long-term biofilter operation: filling with water and draining, backwashing, and air sparging. Several flow rates and temperatures $\left(20-60^{\circ} \mathrm{C}\right)$ were applied using either water or different chemicals ( $\mathrm{NaOH}, \mathrm{NaOCl}, \mathrm{HTAB})$ in aqueous solution. Usually, higher flow rates and higher temperatures allowed the removal of more biomass, but the efficiency of biomass removal was highly dependant on the pressure drop reached before the treatment. The filling/draining method was the least efficient for biomass removal, although the treatment did basically not generate any biological inhibition. The efficiency of backwashing and air sparging was relatively similar and was more effective when adding chemicals. However, treatments with chemicals resulted in a significant decrease of the biofilter's performance immediately after applying the treatment, needing periods of several days to recover the original performance. The effect of manually mixing the packing material was also evaluated in duplicate experiments. Quite large amounts of biomass were removed but disruption of the filter bed was observed. Batch assays were performed simultaneously in order to support and quantify the observed inhibitory effects of the different chemicals and temperatures used during the treatments.
\end{abstract}

\section{Keywords}

Air sparging; Backwashing; Biofilm; Clogging; Modeling; Plug flow 


\section{Introduction}

The removal of VOCs from gaseous streams can be done by means of processes like absorption, adsorption, incineration and, more recently, biofiltration [1]. In biofiltration, a polluted air stream flows through a filter bed colonized by microorganisms that mineralize the toxic compound. Biofiltration has been applied successfully for the treatment of many different pollutants [2]. It appears to be one of the most attractive technologies regarding both effectiveness levels and costs, over a wide range of flow rates and at pollutant concentrations below approximately $5 \mathrm{~g} \mathrm{~m}^{-3}[1]$. Toluene is a frequently encountered air pollutant. In a large number of countries, its discharge to the environment is hardly controlled, although ever more stringent regulations have appeared in many industrialized countries [3]. Toluene is biodegradable and biofiltration has proven to be a suitable method to eliminate it from air streams [4], [5], [6], [7], [8] and [9].

For a long-term stable continuous operation of packed bed biofilters fed high loads of pollutant(s), it is essential to prevent clogging and chaneling problems due to excessive growth of the biolayer, compaction and degradation of the filter bed. Such problems are related to deviations from ideal flow regimes and lead to a reduced biofilter performance. Basically no data have been published on the long-term hydrodynamic behaviour of gas phase biofilters used for air pollution control. Near ideal plug flow may be the rule in many cases with clean carriers and during start-up, but the situation is expected to be different after heavy biofilm growth. In order to reduce clogging and chaneling problems, a few techniques have recently been tested and reported in the literature aimed at limiting problems related to the accumulation of excess biomass and clogging material [10], [11], [12], [13], [14], [15], [16] and [7].

In the present study, hydrodynamics of gas phase biofilters packed with an inert carrier were studied, and deviations from ideal plug flow regime were estimated. Residence time was calculated both for the bulk gas phase and for the pollutant, on start-up and after 2-year operation. A comparison is then also done between several techniques suitable for removing biomass from biofilters after long-term operation, in order to determine the most viable methods from a technical point of view; considering the amount of biomass removed and the effect of the technology on biofilter performance. The studies are completed with some batch assays, aimed at checking the effect of various chemicals and different temperatures used in the backwashing and air sparging procedures on the biodegradation efficiency.

\section{Materials and methods}

\subsection{Biofilter}

The reactor consisted of a glass column packed with perlite as described elsewhere [6]. The top free section of the reactor was about $22 \mathrm{~cm}$ high, allowing fluidization of the filter bed, whenever necessary. All the surfaces in contact with polluted air were made of glass, Teflon ${ }^{\mathrm{TM}}$ or Viton ${ }^{\mathrm{TM}}$. The bioreactor was wrapped in aluminium foil in order to prevent the growth of algae.

A downward air flow was fed to the biofilter. Part of the air stream flew through a humidification tank submerged in a temperature-controlled water bath. Another fraction 
of the air flow was used to volatilize the pollutant, i.e. toluene, in a stripping bottle. The flow rates of both gas streams were measured and regulated with flow meters. The streams entered a mixing chamber before flowing through the biofilter. The empty bed gas residence time (EBRT) was initially maintained at $56 \mathrm{~s}$. Toluene loading rate (TL, $\mathrm{g} \mathrm{m}^{-3} \mathrm{~h}^{-1}$ ), elimination capacity (EC, $\mathrm{g} \mathrm{m}^{-3} \mathrm{~h}^{-1}$ ) and removal efficiency (RE, \%) were used for evaluating the biofilter's performance [1].

\subsection{Organisms and culture media}

A defined bacterial-fungal consortium [17] was originally used to inoculate the biofilter, but when starting the studies on biomass removal, more than 2 years after start-up, the microbial culture present in the reactor was composed of a more complex bacterialfungal community. Once a week, the reactor was fed a nutrient solution as described elsewhere [8]. $\mathrm{pH}$ was not regulated in order to allow comparison with previous results, and acidification of the filter bed was observed. The $\mathrm{pH}$ most often dropped from $6.0 \pm 0.1$ to $4.5 \pm 0.5$. The efficiency of such perlite-packed biofilter is highly reproducible and, as published before [8] and [6], in the present case also elimination capacities of around $70 \mathrm{~g} \mathrm{~m}^{-3} \mathrm{~h}^{-1}$ were already obtained soon after inoculation with removal efficiencies above $95 \%$.

\subsection{Hydrodynamics}

The hydrodynamics of the biofilter were determined by means of pulse tracer experiments. Either methane or styrene were used as tracer to estimate the mean residence time of, respectively, the bulk gas phase and the pollutant. Samples were taken at the outlet of the biofilter with a gas-tight syringe and were directly analyzed on the GC. The data were adjusted to the tanks-in-series model.

\subsection{Excess biomass removal}

The methods used for biomass removal are schematically explained in Fig. 1. For the water-filling/draining experiment, the biofilter was first filled either with water or with a nutrient solution, and later drained off. In the backwashing treatments, $5 \mathrm{~L}$ water (treatment water) was used, at room temperature (control) and at $30^{\circ} \mathrm{C}, 45^{\circ} \mathrm{C}$ and $60^{\circ} \mathrm{C}$. Different water flow rates were tested. In each case, the aqueous phase was recycled through the biofilter for $30 \mathrm{~min}$ and then drained off. At the end of the treatments, the filter bed was washed with $2 \mathrm{~L}$ distilled water ("washwater" or "rinse water"). Nevertheless, in a preliminary backwashing experiment water was not recycled. In such case, different volumes of water were fed to the reactor for $15 \mathrm{~min}$, at different flow rates and without recycling (not shown in Fig. 1). In the case of air sparging experiments, an upward air flow was sparged through the water-filled packing material. At the end of the operation, the aqueous phase was drained off and $1 \mathrm{~L}$ clean water (wash water) was used to rinse the packing. Different flow rates and temperatures $\left(30^{\circ} \mathrm{C}, 45^{\circ} \mathrm{C}, 60^{\circ} \mathrm{C}\right)$ were studied. Assays at room temperature were used as control. Treatments with chemicals were carried out with $\mathrm{NaOH}, \mathrm{NaOCl}$ or hexadecyltrimethylammonium bromide (HTAB) solutions. These solutions were prepared both for use in backwashing and air sparging experiments, although the cationic detergent (HTAB) was not used in case of air sparging because of foaming problems previously observed in the backwashing studies. Each experiment was performed at least in duplicate in order to calculate standard deviations, and trying to 
reach similar experimental conditions on each occasion. The total weight of the biofilter as well as VSS concentrations were measured before each experiment in an effort to apply the treatments at similar initial microbial mass.

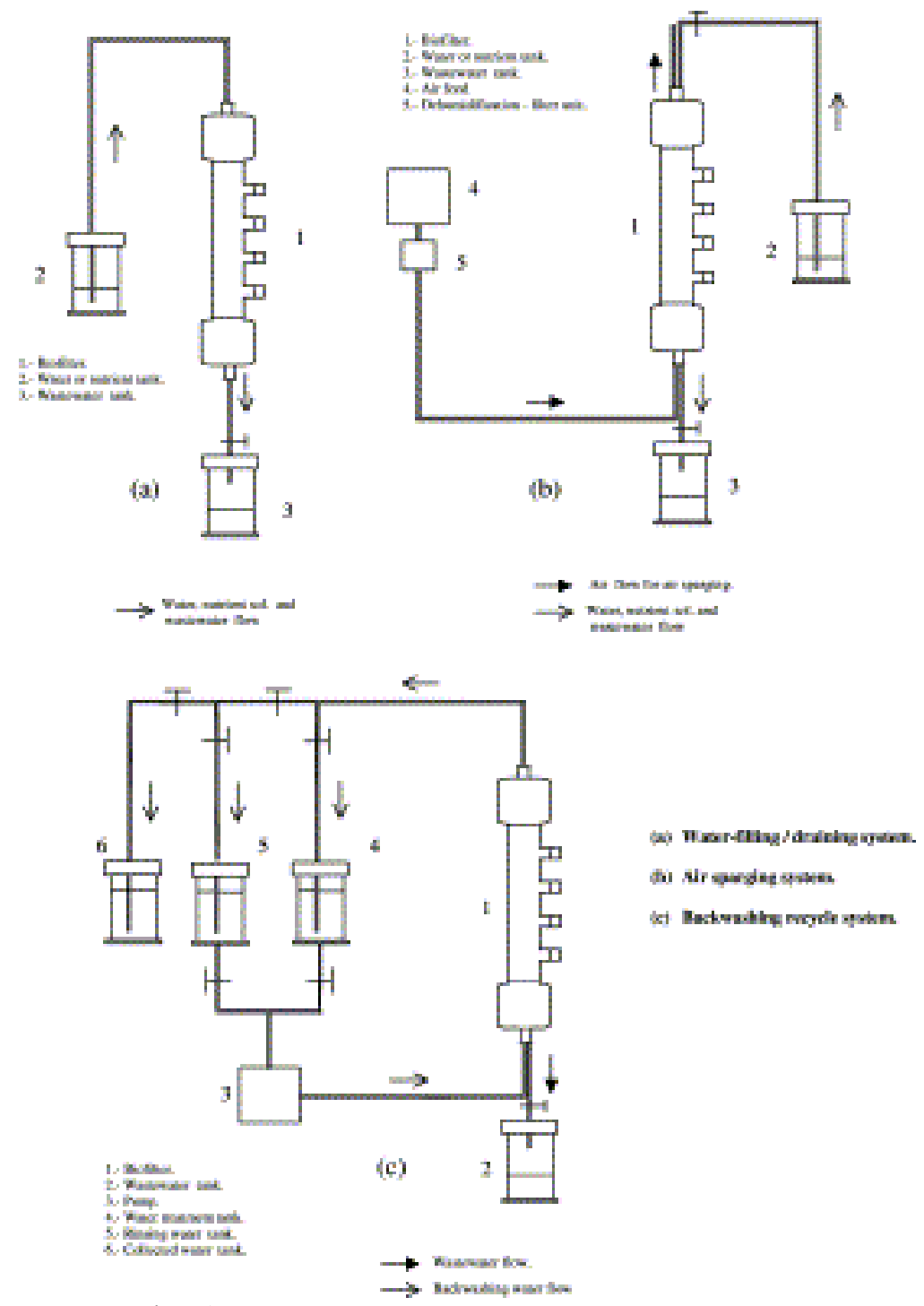

Fig. 1.

Treatment systems used in the different biomass removal technologies.

Finally, at the end of this study two manual-mixing treatments were applied. In this case, the biofilter operation was temporarily stopped; the reactor was unpacked, and the packing material was mixed manually. After being packed again, the nutrient solution was added to the biofilter and then drained off, allowing the removal of detached biomass and any residual inert material. The amount VSS removed is expressed as gram biomass removed ( $\mathrm{g}$ biomass) in the figures.

For each experiment, optical density determination, $\mathrm{pH}$ control, VSS and TSS analysis were performed with all the collected wastewaters (treatment and wash water). 


\subsection{Batch experiments}

All the batch assays were performed as described in Veiga and Kennes [8], using $315 \mathrm{~mL}$-bottles, containing $50 \mathrm{~mL}$ of the aqueous nutritive solution and the inoculum. The initial amount of biomass was $0.3 \mathrm{~g} \mathrm{VSS} \mathrm{L}^{-1}$. For all the assays, the initial $\mathrm{pH}$ was $6.00 \pm 0.02$, and the initial dissolved oxygen concentration was $5.4 \pm 0.1 \mathrm{mg} \mathrm{L}^{-1}$. Toluene was the only carbon source added. Although removal data in batch assays are reported in percentage, the alkylbenzene concentrations both in the liquid and in the gas phase can easily be calculated using Henry's law's constant for toluene $\left(0.27\right.$ at $\left.25^{\circ} \mathrm{C}\right)$, and knowing the amount of toluene added to the bottles (expressed in $\mu \mathrm{L}$ in the figures).

In order to check the influence of temperature, biodegradation assays were performed at room temperature, $30^{\circ} \mathrm{C}, 45^{\circ} \mathrm{C}$ and $60^{\circ} \mathrm{C}$, with different pollutant concentrations, by adding between 4 and $36 \mu \mathrm{L}$ toluene to the bottles. $\mathrm{NaOH}$ concentrations tested in batch assays were $0.05 \%, 0.1 \%, 0.25 \%, 0.5 \%$ and $1 \%(\mathrm{w} / \mathrm{v})$. For $\mathrm{NaOCl}$, concentrations of $0.005 \%, 0.01 \%, 0.05 \%, 0.1 \%, 0.25 \%(\mathrm{w} / \mathrm{v})$ were used, and for HTAB concentrations of $0.01 \%, 0.05 \%$ and $0.1 \%(\mathrm{w} / \mathrm{v})$ were used. In the biomass removal studies with chemical compounds a single concentration of toluene, corresponding to $11 \mu \mathrm{L}$ of the alkylbenzene, was used in batch assays. Biodegradation was followed until toluene had completely disappeared.

\subsection{Analytical methods}

Gas chromatography was used for toluene analysis [8]. The concentrations were calculated by comparing the GC area of the sample to the one obtained with an external standard of known alkylbenzene concentration.

The optical density was measured at $660 \mathrm{~nm}$ with an UV/V Perkin-Elmer spectrophotometer using distilled water as a blank. VSS and TSS analysis were performed after ending the experiments. Samples from residual, recycle and rinse water were analyzed in duplicate according to Methods 2540C (TSS) and 2540E (VSS) of Standard Methods [18]. A Crison pH-meter (model 507) connected to an Ingold electrode (model U455-S7) was used for $\mathrm{pH}$ determinations. Pressure drop was measured using a Warburg manometer expressing the results in $\mathrm{cm} \mathrm{H}_{2} \mathrm{O}$ per meter packed bed.

\section{Results and discussion}

\subsection{Hydrodynamics on start-up}

On start-up, residence time distribution (RTD) curves were obtained using methane as a tracer. A typical RTD curve is shown in Fig. 2. When using the tanks-in-series model, the results yielded a value of $9 \pm 1$ identical stirred tanks in series. Hydrodynamics can also be expressed by means of the adimensional Bodenstein number (Bo) defined as $\mathrm{Bo}=(v L / \mathrm{Da})$, where $v$ is the superficial air velocity, $L$ is the reactor length and $\mathrm{Da}$ is the dispersion coefficient. If $N$ represents the number of identical stirred tanks in series and assuming that $N=(\mathrm{Bo} / 2)+1$, then Bo would be approximately equal to 16 , a value close to typical plug flow conditions. The mean residence time, calculated from the data of the RTD curves, was $39 \mathrm{~s}$. Very little information has been reported on hydrodynamics of gas-phase biofilters and the few published results mainly deal with organic carriers 
rather than inert ones. The authors do not always specify when the experiments were undertaken, although all were most probably performed on start-up. Devinny et al. [19] report a Bo number of 52 and Sabo [20] mention Bo values ranging from 40 to 200 for organic carriers; which is, in both cases, higher than a value of 20 above which near ideal plug flow conditions may be considered.

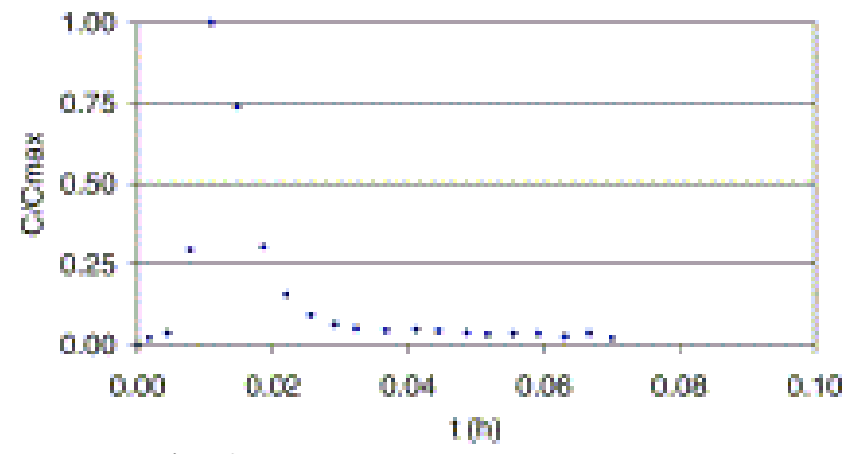

Fig. 2.

Typical RTD curve on start-up using methane as a tracer.

\subsection{Hydrodynamics after 2-year operation}

The RTD pattern was also evaluated after 2-year biofilter operation when heavy biofilm accumulation was clearly observed. By that time, the optimal elimination capacity was around $65-70 \mathrm{~g} \mathrm{~m}^{-3} \mathrm{~h}^{-1}$ with removal efficiencies above $90 \%$. Compared to the data obtained during start-up, a more significant deviation from ideal plug flow was observed as can also easily be seen in the typical curve with a non-negligible tail shown in Fig. 3. In other assays, the tail was shorter. The reproducibility of the RTD experiments was worse than in the previous case, leading to $5 \pm 2$ identical stirred tanks in series, corresponding to a Bo value of $8 \pm 4$. The same assays were repeated a few weeks later, leading to very similar results. The assymetric distribution of the curve and the tail suggest the presence of dead zones and chaneling. The present data are of significant practical interest since gas-phase biofilters are usually considered to behave as ideal plug flow reactors and such assumption does affect both modeling and performance which drops under non-ideal flow regime.

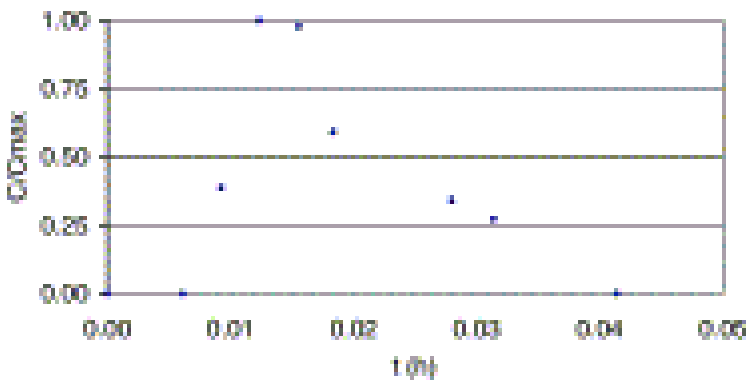

Fig. 3.

Typical RTD curve after more than 2-year operation using methane as a tracer. 


\subsection{Retention time of the pollutant}

Basically any organic pollutant adsorbs to some extent to solid surfaces and will be absorbed in the liquid film present on the packing. Solid surfaces playing the role of adsorbents include the carrier material and biomass related compounds, i.e. microorganisms, microbial exopolymers, etc. The pollutant will thus be retained for a longer period in the biofilter than the mean residence time of bulk gas. This increase in residence time was estimated by calculating the mean residence time of styrene obtained from the RTD curve during start-up and at the beginning of the second year operation. Styrene was selected as the tracer for two main reasons. First of all, because it is chemically similar to toluene, the pollutant fed to the biofilters. Secondly, because it was not biodegraded by the microbial population attached on the carrier when undertaking the RTD studies. According to the data obtained, the mean residence time for styrene was $185 \mathrm{~s}$ on start-up and $990 \mathrm{~s}$ on the second year operation, which are significantly higher values than obtained for methane. This can be explained by the lower volatility and higher density of styrene (and toluene) compared to methane (and air), and to the adsorption of the pollutant onto the biofilm above all after long-term operation and heavy biomass growth.

\subsection{Water filling/draining, air sparging and backwashing with water}

Different assays were then undertaken to avoid excess biomass accumulation and deviations from plug flow behaviour. In a first set of experiments, different methods used for removing excess biomass after 2-year operation were applied in the presence of water only, without the addition of any chemical. Fig. 4 shows the amount of biomass removed in the case of air sparging and backwashing experiments at different water or air flow rates. As a matter of fact, in the case of the water-filling/draining treatment no water nor air flow was applied and, therefore, only one result appears in Fig. 4. In that case, the amount of biomass removed was low compared to the other methods, since only about $0.1 \mathrm{~g}$ VSS was removed with the $2 \mathrm{~L}$ distilled water used during the treatment. Applying such technique, already used routinely in our laboratory in previous studies for feeding a nutrient solution [8], resulted in basically no inhibition of VOC removal after the treatment. In backwashing and air sparging experiments with water, the biofilter's efficiency slightly dropped after the treatment to recover its optimal performance in $8-10 \mathrm{~h}$. Average loads around $65-70 \mathrm{~g} \mathrm{~m}^{-3} \mathrm{~h}^{-1}$ with removal efficiencies $>95 \%$ could be maintained with such methods.

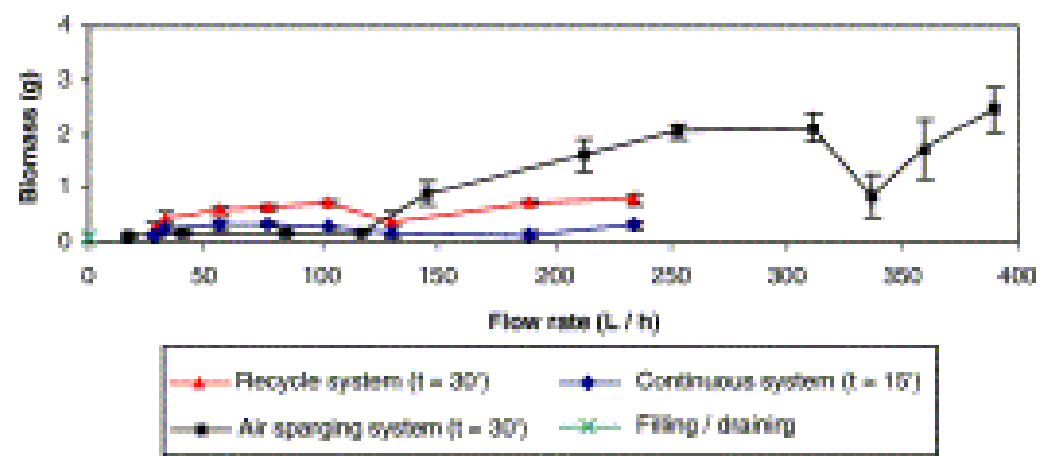

Fig. 4.

Amount of biomass removed using different flow rates in case of backwashing (recycle and continuous system), air sparging and filling/draining. 
At high flow rates, the amount of biomass removed increased when increasing either the water (backwashing) or the air (air sparging) flow rate, mainly at the highest flow rates tested, at which higher amounts of biomass were removed. Other authors working with wastewaters did also observe that increasing the superficial velocity of a fluid usually increases biofilm detachment from solid supports [21]. As can be seen in Fig. 4, backwashing was more efficient at low flow rates and air sparging was the most efficient technique at high flow rates. The higher efficiency of the three-phase air sparging technique (solid/liquid/gas) compared to the two-phase backwashing strategy (solid/liquid) must have resulted from increased turbulence and abrasion in air sparging [21]. It is worth noting that, in the air sparging experiments performed at 337 and $359 \mathrm{~L} \mathrm{~h}^{-1}$, lower amounts of biomass were removed on an average compared to the other results at high flow rates (Fig. 4), which can be explained by the pressure drop values. Indeed, it was observed that before each treatment reported in Fig. 4, the pressure drop over the biofilter was low, between 0.5 and $2.0 \mathrm{~cm} \mathrm{H}_{2} \mathrm{O}$ per meter packed bed, except for the air sparging experiments at 337 and $359 \mathrm{~L} \mathrm{~h}^{-1}$, where the amount of biomass removed decreased and the pressure drop before the treatment reached higher values of 6.7 and $4.0 \mathrm{~cm} \mathrm{H} \mathrm{H}_{2} \mathrm{O}$ per meter, respectively. This observation suggests that the efficiency of biomass removal decreases at higher pressure drops over the biofilter as will be illustrated more in details and discussed in the last section of this paper. As will be described below, none of the treatments allowed to remove as much biomass as when adding chemicals.

\subsection{Backwashing with $\mathrm{NaOH}$ solutions}

Results of backwashing treatments with $0.05 \% \mathrm{NaOH}$ solutions indicated that this is an effective though quite aggressive method (Fig. 5). Special care was taken in washing the filter bed after the treatments in order to avoid significant $\mathrm{pH}$ increases. Nevertheless, after the treatment the biofilter presented a low biological activity compared to the biofilter's performance before the treatment, although relatively large amounts of VSS were found in the residual and wash waters (Fig. 5) compared to the treatment with water only. The $\mathrm{pH}$ of the system increased from its usual value of 4-5 to about 7-7.5. The elimination capacity dropped to about $40 \mathrm{~g} \mathrm{~m}^{-3} \mathrm{~h}^{-1}$ at an average load of $65 \mathrm{~g} \mathrm{~m}^{-3} \mathrm{~h}^{-1}$, resulting in removal efficiencies near $65 \%$ to be compared to the more than 95\% removal efficiency obtained when using pure water. The biofilter needed, in all cases, a period of 3-4 days to recover to its original performance.

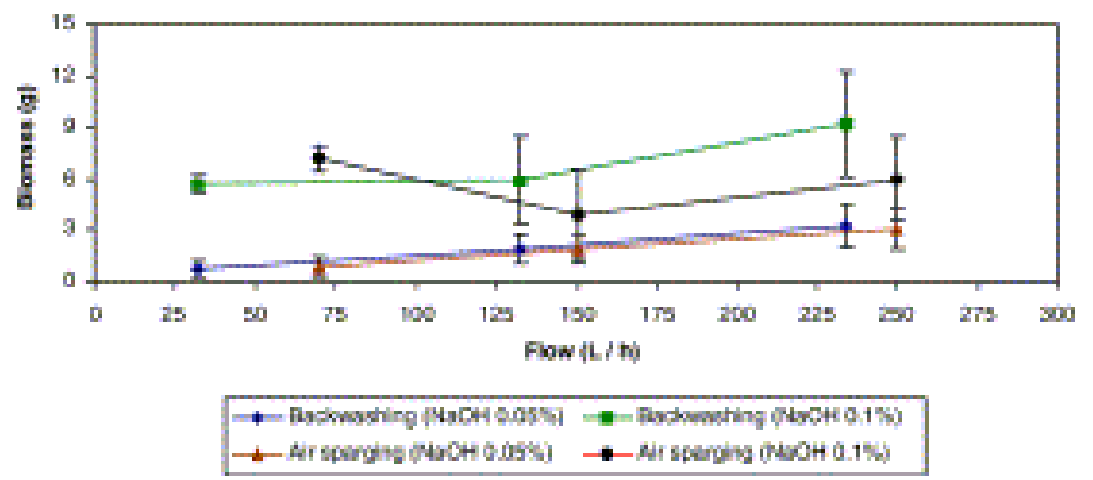

Fig. 5.

Amount of biomass removed at different flow rates in case of backwashing and air sparging with $\mathrm{NaOH}$ solutions. 
As a general rule, when working with higher flow rates, slightly higher amounts of biomass could be removed (Fig. 5). Slightly higher amounts of biomass were also eliminated at the highest $\mathrm{NaOH}$ concentration (0.1\%) (Fig. 5), but, in such case, foaming problems appeared. Cox and Deshusses [12] as well as Weber and Hartmans [22] did also use $\mathrm{NaOH}$ for biomass control and already warned about foam formation when working with $\mathrm{NaOH}$ concentrations above $0.1 \%$. The highest amount of biomass removed was $4.4 \mathrm{~kg} \mathrm{VSS} / \mathrm{m}^{3}$ filter bed $\left(0.1 \% \mathrm{NaOH}\right.$ and $\left.234 \mathrm{~L} \mathrm{~h}^{-1}\right)$ to be compared to $3.2 \mathrm{~kg}$ dry biomass removed per $\mathrm{m}^{3}$ reactor using a $0.1 \% \mathrm{NaOH}$ solution in a biotrickling filter packed with Pall rings [22]. Other authors do usually not mention the exact amount of biomass removed. With $0.1 \% \mathrm{NaOH}$, the biofilter needed also to cope temporarily with a high $\mathrm{pH}$, as its value increased up to 9.0-9.5. It was necessary to abundantly rinse the filter bed with water in order to reach $\mathrm{pH}$ neutrality, unless the rinsing water was previously acidified. However, the use of an acid medium would result in the release of salts and would increase the ionic strength which could have a negative effect on the activity of the biomass. At the end of the treatment, the elimination capacity did not exceed $10 \mathrm{~g} \mathrm{~m}^{-3} \mathrm{~h}^{-1}$ at a toluene load of only $30 \mathrm{~g} \mathrm{~m}^{-3} \mathrm{~h}^{-1}$, representing a removal efficiency of only 33\%, which is much lower than the 65 and $40 \mathrm{~g} \mathrm{~m}^{-3} \mathrm{~h}^{-1}$ reached, respectively, with water and with $0.05 \% \mathrm{NaOH}$.

Batch assays were performed in the presence of $\mathrm{NaOH}$ and toluene (Fig. 6). The initial $\mathrm{pH}$ values were $6.8-7.1$ and $9.2-9.3$ for $0.05 \%$ and $0.1 \% \mathrm{NaOH}$, respectively, when using the same basal aqueous medium as in the biofilter. As expected, biodegradation was inhibited at the highest $\mathrm{NaOH}$ concentration because of the $\mathrm{pH}$ increase above 9.0 which is quite high for any microbial activity and which does also explain the significant inhibition observed in the biofilter. However, at the lowest $\mathrm{NaOH}$ concentration the biodegradation rate was only slightly lower than in the control test, at $\mathrm{pH}$ 6, without $\mathrm{NaOH}$. This does also indicate that the microbiota present in the biofilter was highly (or more) active in a slightly acidic medium than under neutral conditions (pH 6.8-7.1), as was also observed previously in studies with acid tolerant pure cultures isolated from a similar biofilter [17].

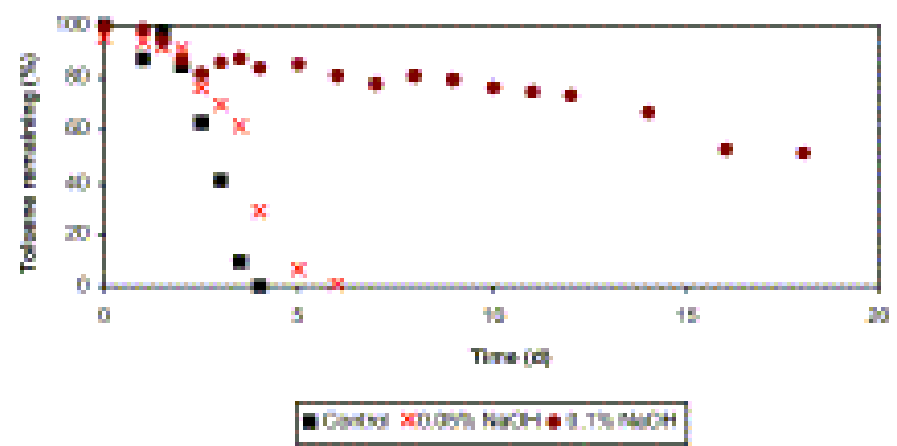

Fig. 6.

Toluene removal in batch assays in the absence of $\mathrm{NaOH}$ and in presence of $0.05 \%$ and $0.1 \% \mathrm{NaOH}$. 


\subsection{Air sparging with $\mathrm{NaOH}$ solutions}

As in the case of backwashing, the data of air sparging experiments with a $0.05 \%(\mathrm{w} / \mathrm{v})$ $\mathrm{NaOH}$ solution again indicate that when increasing the air flow rate, higher amounts of biomass could be removed, and the effect was similar to in the case of backwashing (Fig. 5).

Data collected during the treatments with the $0.1 \%(\mathrm{w} / \mathrm{v}) \mathrm{NaOH}$ solution did not exactly follow the same trend (Fig. 5). Indeed, after applying a flow rate of $70 \mathrm{~L} \mathrm{~h}^{-1}$, in the next experiment at a flow rate of $150 \mathrm{~L} \mathrm{~h}^{-1}$ the amount of biomass removed decreased. It then increased again at the highest flow rate of $250 \mathrm{~L} \mathrm{~h}^{-1}$. This can be explained by the previously mentioned pressure drop effect. Indeed, when undertaking the experiment at the lowest flow rate of $70 \mathrm{~L} \mathrm{~h}^{-1}$, the biofilter presented a low mean pressure drop of about $0.5 \mathrm{~cm} \mathrm{H}_{2} \mathrm{O} / \mathrm{m}$ filter bed. For the first experiment at a flow rate of $150 \mathrm{~L} \mathrm{~h}^{-1}$, the pressure drop had reached a quite higher value, around $10 \mathrm{~cm} \mathrm{H} \mathrm{H}_{2} \mathrm{O} / \mathrm{m}$ packed bed. Two identical additional assays were then performed, after waiting for reaching a lower pressure drop over the filter bed (see also the last section of this paper). The average amount of biomass removed as well as standard deviations are plotted in Fig. 5. This confirms the above-mentioned comment, concluding that the treatments were less efficient when a higher pressure drop was reached in the biofilter when undertaking the experiment of biomass removal. The experiments at $150 \mathrm{~L} \mathrm{~h}^{-1}$ were performed in triplicate. However, because of the high pressure drop during the first assay generating a lower biomass removal, the mean value reported in Fig. 5 is still lower than at $70 \mathrm{~L} \mathrm{~h}^{-1}$. Nevertheless, the general tendency is quite clear. As for the backwashing treatments, the $\mathrm{NaOH}$ concentration had a clear influence on the biomass removal efficiency, being more biomass removed with $0.1 \%(w / v)$ than with $0.05 \% \mathrm{NaOH}(\mathrm{w} / \mathrm{v})($ Fig. 5).

Foaming and a high $\mathrm{pH}$ were the main problems after applying the $\mathrm{NaOH}$ treatment; foaming phenomena being enhanced when sparging air through the system. When working with a $0.1 \%(\mathrm{w} / \mathrm{v}) \mathrm{NaOH}$ solution, the biofilm reached a final $\mathrm{pH}$ of 9.2-9.8 which was inhibitory (Fig. 6), and it was necessary to rinse the filter bed with water until slightly acidic conditions were reached again. This was not necessary in the air sparging experiments with the $0.05 \%(\mathrm{w} / \mathrm{v}) \mathrm{NaOH}$ solution since, after the treatment, the final $\mathrm{pH}$ was 7.4-7.8 which was still satisfactory for the biofilter, although some inhibition was observed. Basically identical inhibitory effects were observed in backwashing assays as in air sparging experiments.

Furthermore the efficiency of the air sparging technology and backwashing with $\mathrm{NaOH}$ solutions are compared in Fig. 5. Although similar amounts of biomass were removed, for a given set of flow rates and $\mathrm{NaOH}$ concentrations, lower volumes of aqueous phase were used for air sparging. In the latter case, the total volume of $\mathrm{NaOH}$ solution and rinsing water was $5 \mathrm{~L}$, to be compared to the $9 \mathrm{~L} \mathrm{NaOH}$ solution and rinsing water needed during backwashing treatments.

\subsection{Backwashing with $\mathrm{NaOCl}$ solutions}

Good results were expected with $\mathrm{NaOCl}$ solutions, considering its strong germicide effect, and taking into account the recent data of Cox and Deshusses [12] suggesting a high biomass removal efficiency. Comparing Fig. 5 and Fig. 7 indicates that relatively low concentrations of sodium hypochlorite $(0.005 \%$ and $0.01 \%)$ allowed eliminating 
larger amounts of biomass than backwashing treatments with $0.05 \% \mathrm{NaOH}$, and yielded relatively similar results as in backwashing assays with $0.1 \% \mathrm{NaOH}$. After the treatment with $0.005 \% \mathrm{NaOCl}$, the biofilter's elimination capacity dropped down to values below $40 \mathrm{~g} \mathrm{~m}^{-3} \mathrm{~h}^{-1}$ at a toluene load of $60 \mathrm{~g} \mathrm{~m}^{-3} \mathrm{~h}^{-1}$, needing a period of almost 1 week to recover a removal efficiency above $80 \%$.

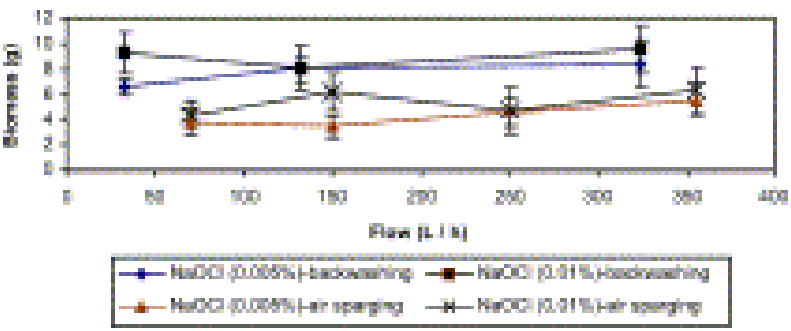

Fig. 7.

Amount of biomass removed in backwashing and air sparging with $\mathrm{NaOCl}$ solutions, at different flow rates.

The amount of biomass removed was quite similar at the different flow rates for a given concentration of $\mathrm{NaOCl}$ over the range of flow rates tested, although biomass removal did weakly increase with the flow rate. When increasing the concentration of hypochlorite from $0.005 \%$ to $0.01 \%$, slightly higher amounts of biomass could be removed. It is worth mentioning that the pressure drop over the biofilter was always below $2 \mathrm{~cm} \mathrm{H}_{2} \mathrm{O}$ per meter packed bed just before applying the treatments, except for the backwashing experiment with $0.01 \% \mathrm{NaOCl}$ at a flow rate of $132 \mathrm{~L} \mathrm{~h}^{-1}$, for which a slightly higher average pressure drop was reached. The germicide effect of the $0.01 \%$ $\mathrm{NaOCl}$ concentration was relatively important, resulting in the almost total inhibition of toluene biodegradation ( $\mathrm{RE}<10 \%$ ) for a few days. Afterwards, the removal efficiency again increased from about $10 \%$ to $>90 \%$ in 10 days.

Batch assays support the above reported germicide effect of $\mathrm{NaOCl}$ solutions and the negative effect on the elimination rate of toluene as shown in Fig. 8. In batch assays with concentrations above $0.025 \% \mathrm{NaOCl}(\mathrm{w} / \mathrm{v})$, toluene was not degraded at all (data not shown).

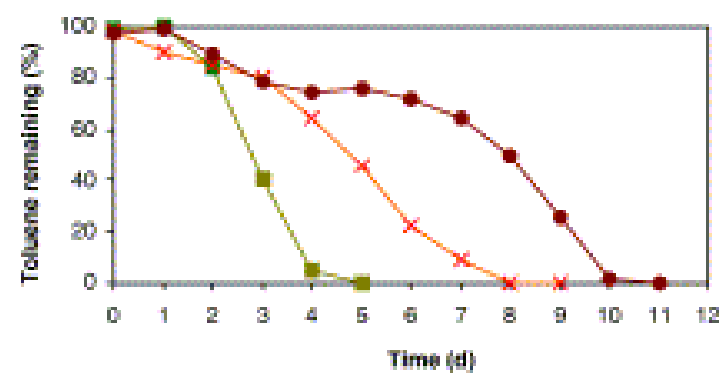

- Control $\rightarrow-0.005 \% \mathrm{NaCCl} \rightarrow-0.01 \% \mathrm{NaCC}$

Fig. 8.

Removal of toluene in batch assays in the absence of $\mathrm{NaOCl}$ and in presence of $0.005 \%$ and $0.01 \% \mathrm{NaOCl}$. 


\subsection{Air sparging with $\mathrm{NaOCl}$ solutions}

$\mathrm{NaOCl}$ solutions of 0.005 and $0.01 \%(\mathrm{w} / \mathrm{v})$ were used at four different flow rates, 70 , 150, 250 and $355 \mathrm{~L} \mathrm{~h}^{-1}$, at $20^{\circ} \mathrm{C}$ (Fig. 7). Higher amounts of biomass were removed compared to the results of the treatments with $0.05 \% \mathrm{NaOH}$ solutions, but the data were relatively similar or even slightly worse than in the assays with $0.1 \% \mathrm{NaOH}$. The amounts of biomass removed were higher when increasing either the flow rate or the $\mathrm{NaOCl}$ concentration, although the influence of the flow rate was less significant than the effect of the hypochlorite concentration (Fig. 7). The best results were obtained with $0.01 \% \mathrm{NaOCl}(\mathrm{w} / \mathrm{v})$, allowing to remove $6.35 \mathrm{~g} \mathrm{VSS}$ at a flow rate of $355 \mathrm{~L} \mathrm{~h}^{-1}$. When working with a $0.005 \% \mathrm{NaOCl}$ solution and a flow rate of $355 \mathrm{~L} \mathrm{~h}^{-1}, 5.6 \mathrm{~g}$ VSS was the largest amount of biomass removed. At the end of the experiments, the $\mathrm{pH}$ of the biofilter was between 4.6 and 5.4 and its elimination capacity was around or slightly below $20 \mathrm{~g} \mathrm{~m}^{-3} \mathrm{~h}^{-1}$ at a toluene load of $50 \mathrm{~g} \mathrm{~m}^{-3} \mathrm{~h}^{-1}$, corresponding to a removal efficiency of $40 \%$.

\subsection{Backwashing with HTAB}

As summarized in the literature [22], [23] and [24], it is known that most microorganisms present negative charges in their cell wall, integrating electrostatic forces that help them attach to the biofilm structure, jointly with polyanionic matrix polymers (polysaccharides) and metal bridge cations. In order to try and eliminate the charge interactions the next strategy consisted in using a cationic detergent, namely an ammonium salt. The experimental results are shown in Fig. 9. Two concentrations $(0.01 \%$ and $0.05 \%)$ and three different flow rates were tested. As observed in Fig. 9, very similar and relatively low amounts of biomass were removed with both concentrations. The flow rate appeared to have a limited effect on the results. Foaming was the major problem. The activity of the biomass in the biofilter was partly inhibited after applying this treatment but it was not as strong as in the treatments with $\mathrm{NaOH}$ or $\mathrm{NaOCl}$ and was similar as in backwashing assays with water, needing less than 1 day to recover removal efficiencies of at least $90 \%$.

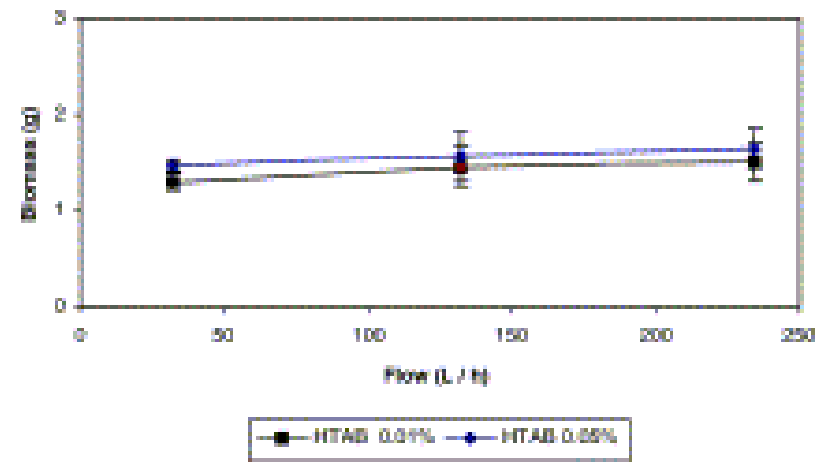

Fig. 9.

Amount of biomass removed in backwashing treatments at different flow rates, in presence of HTAB.

Batch assays were performed in the presence of toluene and $0.01 \%$ and $0.05 \% \mathrm{HTAB}$ as used in the biofilter. The assays indicated that, at such concentrations, HTAB had hardly any inhibitory effect on the microbial activity (data not shown). HTAB was not 
tested in air sparging assays since its effect on biomass removal appeared to be very limited.

\subsection{Backwashing with water at different temperatures}

When carrying out backwashing experiments with water and different combinations of temperatures and flow rates, little biomass was removed at $30^{\circ} \mathrm{C}$ (Fig. 10) and similar results were obtained as at $20^{\circ} \mathrm{C}$ (Fig. 4). The amount of biomass removed was significantly higher at higher temperatures of 45 and, above all, $60^{\circ} \mathrm{C}$ (Fig. 10), mainly when working at high flow rates, although the amount of biomass removed was still quite lower than when using chemicals. After the treatments, the biofilter recovered relatively fast its original temperature. The inhibition was very limited and similar as in the previous experiments with $\mathrm{HTAB}$, needing between a few hours $\left(30^{\circ} \mathrm{C}\right)$ and less than 1 day $\left(60^{\circ} \mathrm{C}\right)$ to recover.

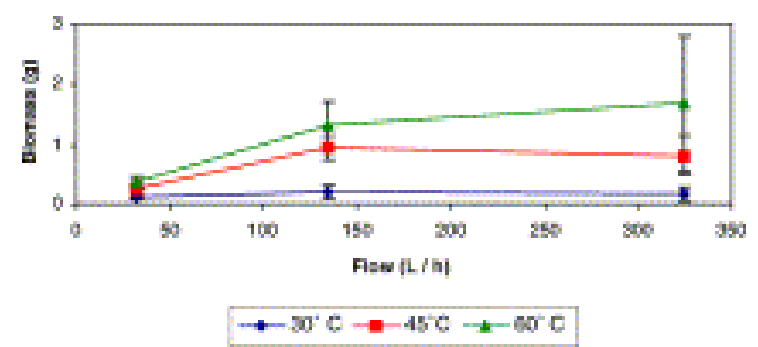

Fig. 10.

Influence of temperature on biomass removal in backwashing treatments, applying different flow rates.

\subsection{Air sparging at different temperatures}

In air sparging experiments, larger amounts of biomass could be removed as the air flow rate was increased (Fig. 11). The effect was more notorious at higher flow rates, exceeding $340 \mathrm{~L} \mathrm{~h}^{-1}$. By comparing data obtained at $30^{\circ} \mathrm{C}$ and $45^{\circ} \mathrm{C}$ it appears that such temperature increase did hardly improve the efficiency of the process. In contrast, the amount of biomass removed at $60^{\circ} \mathrm{C}$ was relatively higher than at the lower temperature tested, reaching the highest biomass removal efficiency at the highest flow rates.

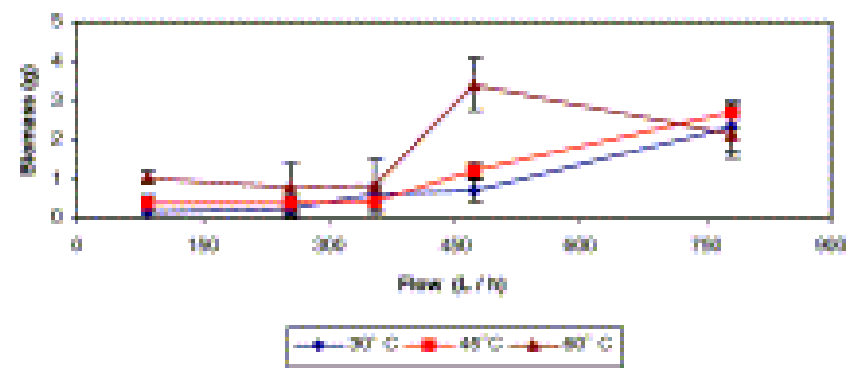

Fig. 11.

Influence of temperature on biomass removal in air sparging treatments, applying different flow rates. 


\subsection{Manual mixing of the filter bed}

Manual-mixing experiments were performed in duplicate. Related techniques have been described for biomass regulation [9] or simply for homogenization of a clogged organic filter bed [4]. After applying manual mixing, the biofilter was rinsed with $3 \mathrm{~L}$ water. Large amounts of biomass were removed but much bed material was disrupted and part of the filter bed was lost in the drain water. The amount of biomass removed reached 12.3 and $10.2 \mathrm{~g}$ VSS for each experiment, which are higher values than in all other cases but, as indicated by Laurenzis et al. [14], stirring is an expensive method. The inhibitory effect of mixing was relatively limited although the biofilter still lasted about 3 days to reach the original performance observed before the treatment.

\subsection{Effect of the pressure drop on the efficiency of biomass removal}

It has been mentioned above that the pressure drop measured over the filter bed directly affects the efficiency of the technique used for biomass removal. Such phenomenon led sometimes to slight deviations from the general tendency of the data. It is well known that the pressure drop is related to the compaction level of the filter bed, chaneling, and clogging. Fig. 12 shows a typical relationship between the amount of biomass removed and the pressure drop before applying the treatment, for an air sparging experiment. This example leads to the conclusion that, when applying the biomass removal strategy, a higher pressure drop results in lower biomass removal. Similar results, leading to the same conclusion were obtained with other treatments used for biomass removal. All the treatments described above were performed at least in duplicate, but some experiments were repeated three times or more, in order to reach reliable data, whenever less biomass was removed than clearly expectable from the general tendency of the results or when a given result did significantly vary from its duplicate. Therefore, standard deviation data have also been plotted in all cases.

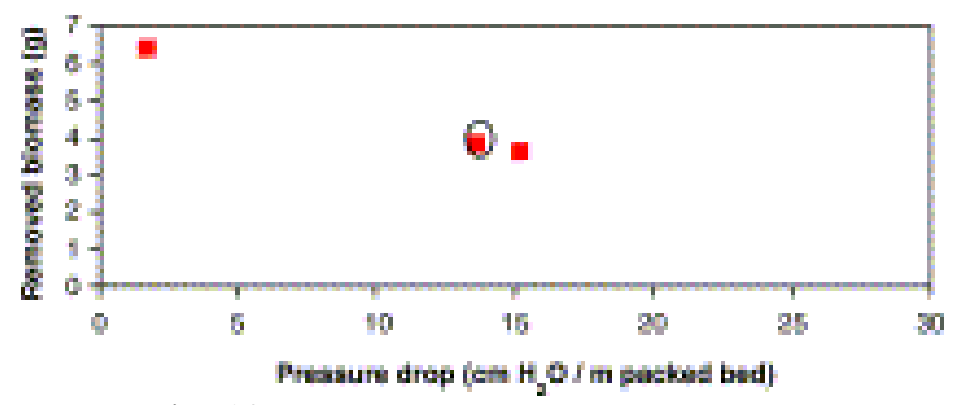

Fig. 12.

Effect of pressure drop on the amount of biomass removed in an air sparging experiment performed in triplicate, with $\mathrm{NaOH}$ and a flow rate of $150 \mathrm{~L} \mathrm{~h}^{-1}$. The circled data represents the average value. 


\section{Conclusions}

In long-term biofilter operation deviation from ideal plug flow regime is non-negligible compared to the start-up period, among others because of heavy biomass accumulation. Different techniques have been tested in order to remove excess biomass.

In the filling/draining method only little biomass could be removed. However, that technique had basically no inhibitory effect on the activity of the biofilm.

Backwashing and air sparging in presence of a water phase were more efficient techniques. The addition of chemicals as $\mathrm{NaOH}$ or $\mathrm{NaOCl}$ to the aqueous phase allowed the elimination of significantly more biomass than when using water only. Nevertheless, when using chemicals the performance of the biofilter dropped significantly immediately after the treatment and the reactor needed several days to recover its original performance while only a few hours were necessary in presence of pure water. Contrary to $\mathrm{NaOH}$ and $\mathrm{NaOCl}$, the addition of HTAB did hardly improve biomass removal compared to assays without chemicals.

As a general rule, more biomass was removed when increasing either the air (air sparging) or water (backwashing) flow rate. The efficiency of biomass removal did also improve whenever increasing the temperature of the water phase $\left(30-60^{\circ} \mathrm{C}\right)$. The inhibitory effect of heat on the biofilm's activity was much more limited than when adding chemicals and the system recovered its original performance usually in less than 1 day.

The highest amount of biomass removed was obtained when unpacking the biofilter and manually mixing the packing material. However, this method, would probably not be viable in full scale biofilters.

As a general rule, the efficiency of the different techniques used for biomass removal decreased whenever a higher pressure drop was reached before the treatment.

\section{Acknowledgments}

Funding for this research was obtained through projects REN2000-0218-P4-02 and PPQ2001-0557.

\section{References}

C. Kennes, M.C. Veiga

Bioreactors for waste gas treatmentKluwer Academic Publishers, Dordrecht, The Netherlands (2001)

C. Kennes, F. Thalasso

Waste gas biotreatment technology

J Chem Technol Biotechnol, 72 (1998), pp. 303-319 
R. Oosting, L.G.C.M. Urlings, P.H. van Riel, C. van Driel

Biopur: alternative packaging for biological systems

A.J. Dragt, J. van Ham (Eds.), Biotechniques for air pollution abatement and odour control policies, Elsevier Science Publishers BV, Amsterdam, NL (1992), pp. 63-70

R. Auria, G. Frere, M. Morales, M.E. Acuña, S. Revah

Influence of mixing and water addition on the removal rate of toluene vapors in a biofilter

Biotechnol Bioeng, 68 (2000), pp. 448-455

H. Jorio, K. Kiared, R. Brzezinski, A. Leroux, G. Viel, M. Heitz

Treatment of air polluted with high concentrations of toluene and xylene in a pilot-scale biofilter

J Chem Technol Biotechnol, 73 (1998), pp. 183-196

O.J. Prado, J.A. Mendoza, M.C. Veiga, C. Kennes

Optimization of nutrient supply in a downflow gas-phase biofilter packed with an inert carrier

Appl Microbiol Biotechnol, 59 (2002), pp. 567-573

P. Schönduve, M. Sára, A. Friedl

Influence of physiological relevant parameters and biomass formation in a trickle-bed bioreactor used for waste gas cleaning

Appl Microbiol Biotechnol, 45 (1996), pp. 286-292

M.C. Veiga, C. Kennes

Parameters affecting performance and modeling of biofilters treating alkylbenzenepolluted air

Appl Microbiol Biotechnol, 55 (2001), pp. 254-258

S-.M. Wübker, A. Laurenzis, U. Werner, C. Friedrich

Controlled biomass formation and kinetics of toluene degradation in a bioscrubber and in a reactor with a periodically moved trickle-bed

Biotechnol Bioeng, 55 (1997), pp. 686-692

C. Alonso, M.T. Suidan, G.A. Sorial, F. Lee Smith, P. Biswas, P.J. Smith, R.C. Brenner Gas treatment in trickle-bed biofilters: biomass, how much is enough?

Biotechnol Bioeng, 54 (1997), pp. 583-594

Cox HHJ, Deshusses MA. Biomass control in waste air biotrickling filters by protozoan predation. Biotechnol Bioeng 1999a; 62:216-24.

Cox HHJ, Deshusses MA. Chemical removal of biomass from waste air biotrickling filters: screening of chemicals of potential interest. Water Res 1999b; 33:2383-91.

C. Kennes, M.C. Veiga

Inert filter media for the biofiltration of waste gases-characteristics and biomass control

Rev Environ Sci Bio Technol, 1 (2002), pp. 201-214 
A. Laurenzis, H. Heits, S-.M. Wubker, U. Heinze, C. Friedrich, U. Werner

Continuous biological waste gas treatment in stirred trickle-bed reactor with discontinuous removal of biomass

Biotechnol Bioeng, 57 (1998), pp. 497-503

M.J. Rihn, X. Zhu, M.T. Suidan, B.J. Kim, B.R. Kim

The effect of nitrate on VOC removal in trickle-bed biofilters

Water Res, 31 (1997), pp. 2997-3008

F.L. Smith, G.A. Sorial, M.T.W. Suidan, A. Breen, P. Biswas

Development of two biomass control strategies for extended, stable operation of highly efficient biofilters with high toluene loadings

Environ Sci Technol, 30 (1996), pp. 1744-1751

M.C. Veiga, M. Fraga, L. Amor, C. Kennes

Biofilter performance and characterization of a biocatalyst degrading alkylbenzene gases

Biodegradation, 10 (1999), pp. 169-176

APHA. Standard methods for the examination of water and wastewater, 17th ed. Washington, DC, USA: American Public Health Association; 1989.

J.S. Devinny, M.A. Deshusses, T.S. Webster

Biofiltration for air pollution controlLewis Publisher, Boca Raton, USA (1999)

Sabo F. Behandlung von Deponiegas im Biofilter. PhD dissertation, University of Stuttgart, Germany, 1991.

F. Trinet, R. Heim, D. Amar, H.T. Chang, B.E. Ritmann

Study of biofilm and fluidization of bioparticles in a three-phase liquid-fluidized bed reactor

Water Sci Technol, 23 (1999), pp. 1347-1354

F.J. Weber, S. Hartmans

Prevention of clogging in a biological trickle-bed reactor removing toluene from contaminated air

Biotechnol Bioeng, 50 (1996), pp. 131-141

V. Korstgens, H.C. Flemming, J. Wingender, W. Borchard

Influence of calcium ions on the mechanical properties of a model biofilm of mucoid Pseudomonas aeruginosa

Water Sci Technol, 43 (2001), pp. 49-57

X. Chen, Ph.S. Stewart

Biofilm removal caused by chemical treatments

Water Res, 34 (2000), pp. 4229-4233 